\title{
Simulation of soil liquefaction due to earthquake loading
}

\author{
Armen Ter-Martirosyan and Ahmad Othman \\ Moscow State Civil Engineering University, 129337, Yaroslavskoe shosse, 26, Moscow, Russia
}

\begin{abstract}
Liquefaction is a phenomenon in which the strength and stiffness of a soil are reduced as a result of seismic or other dynamic effects. Liquefaction was the main reason of the huge damages caused by many earthquakes around the world. The modeling of soil behavior is the main step in the process of predicting the soil liquefaction. Currently, a large number of soil models are presented. However, only some of them can simulate this process. One of these models which can be used is model UBC3D-PLM. In this paper, the possibilities of this model are considered by modeling the seismic impact on a building with its different heights on the PLAXIS software package. The real data of Upland earthquake 1990 near Los Angeles city was used. Results of the simulation showed the difference in the behavior of the soil mass under the influence of an earthquake compared with the elastic behavior, as well as the need to use the UBC3D-PLM model to estimate the seismic impact.
\end{abstract}

\section{Introduction}

Earthquakes are oscillations of a portion of the earth's crust caused by the passage of seismic waves resulted from the short-term release of a large amount of energy.

A characteristic feature of the impact of earthquakes is their short duration, large magnitude of the displacement amplitude at the moment of impact and relatively small amplitudes of subsequent oscillations.

Waves caused by the impact of earthquakes, which spread through the soil particles and the fluid in the pores, can lead to disruption of the structure of the soil mass, and to relatively long process of rearrangement of soil particles under its own weight and external load.

A characteristic feature of a water-saturated, weakly cohesive and loosely soil is its ability to liquefy. Non-cohesive water-saturated soil temporarily turns into a state of heavy viscous fluid, which can lead to loss the stability of buildings and structures at the base on which is located. For that, it is obvious that large mass constructions produce large displacements and rolls, while relatively light ones (buried underground parts of buildings, reservoirs, etc.) raise [7].

In the state of liquefaction, the soil particles are separated and virtually without contact. Compaction occurs due to the mutual displacement of particles (down) and pore fluid (up). The criterion for estimating potential liquefaction can be the critical acceleration arising in the soil under external influences [9].

Quantitative assessment of the stability of soil massifs in case of earthquake, vibration and other types of dynamic effects is associated with the mechanical properties of soils. 
Various models are used to describe the mechanical properties of soils under dynamic effects. They are characterized by a set of equations that determine the behavior of the surroundings.

In this process under consideration, each model corresponds to a certain schematization of properties of the real environment obtained from laboratory and field tests $[1,2]$. The criterion for the applicability of the models is to check the compliance of results of calculations of the stress-strain state of the bases with the observed deformations. The main difference between the models is the nature of the accepted hypotheses regarding the type of physical equations, i.e. principles of deformation and conditions of the limiting state of soils under dynamic effects.

\section{2. Модель UBC3D-PLM}

The UBC3D-PLM model is based on the original UBCSAND model and is an elastoplastic model that allows you to simulate the liquefaction behavior of of sands and silty sands under the influence of seismic loads $[3,4]$.

The assessment of the liquefaction potential of the soil can be performed by analyzing the dynamic effects. To carry out such an analysis, it is possible to use the following algorithm [5]:

- Determination of the geotechnical model of the soil deposit- the horizontal and vertical distribution of engineering and geological elements, groundwater levels, boundary conditions and mechanical properties of soils to describe its behavior under static and dynamic loading.

- Determination of seismic impact according to a specific site and the probabilities of this impact, as indicated in a number of existing regulatory documents $[1,2,6]$.

- $\quad$ Perform calculations using a numerical model and analysis this results.

\subsection{Elastic behavior}

The UBC3D-PLM model includes a non-linear, isotropic law for the elastic behavior, which is determined by the elastic bulk modulus $\mathrm{K}$ and the elastic shear modulus $\mathrm{G}$, which are shown in the following equations:

$$
\begin{aligned}
& K=K_{B}^{* e} p_{\text {ref }}\left(\frac{p^{\prime}}{p_{\text {ref }}}\right)^{m e} \\
& G=K_{G}^{* e} p_{\text {ref }}\left(\frac{p^{\prime}}{p_{\text {ref }}}\right)^{n e}
\end{aligned}
$$

Where $K_{B}^{* e}$ and $K_{G}^{* e}$ are input parameters of the UBC3D-PLM model and represent the module of bulk and shear deformation, respectively, $p_{\text {ref }}$ is reference pressure, $m e$ and $n e$ are parameters that determine the changes in stiffness and stress.

Pure elastic behavior is predicted by the model during the unloading process. The plastic behavior of the material is taken into account when the stress on the yield surface is reached, once the stress decreases below this surface, then it again works elastically.

\subsection{Plastic behavior}

Plastic deformations are formed during the primary and secondary loading and reloading. They are determined by the primary and secondary yield surfaces. Primary loading occurs when the magnitude of the stress exceeds the natural stress state for normally compacted soils and the highest stress value for the over compacted.

After that, the material works within the primary yield surface based on isotropic hardening. As stresses increase, the yield surface transforms, expanding the range of elastic 
behavior of the material. When unloading starts, the material begins to work again elastically. During the re-loading in the case when the stresses do not exceed the previous values - the plastic deformation of the material is less compared to the primary load. This behavior is caused by the kinematic hardening rule for the secondary yield surface, which is activated during the secondary load. Both yield surfaces are defined by the Mohr-Coulomb function, as follows:

$$
f_{m}=\frac{1}{2}\left(\sigma_{\max }^{\prime}-\sigma_{\min }^{\prime}\right)-\left(\frac{1}{2}\left(\sigma_{\max }^{\prime}+\sigma_{\min }^{\prime}\right)+c \cot \emptyset_{p}\right) \sin \emptyset_{\text {mob }}
$$

Where $\sigma_{\text {max }}^{\prime}$ and $\sigma_{\text {min }}^{\prime}$ are, respectively, the maximum and minimum principal effective stresses, $\emptyset_{p}$ и $\emptyset_{m o b}$ are, respectively, peak and mobilized friction angle, $c$ is the cohesion.

The plastic potential function is based on the Drucker-Prager model and can be expressed as follows:

$$
\mathrm{g}_{m}=q-\frac{6 \sin \psi_{m o b}}{3-\sin \psi_{m o b}}\left(p^{\prime}+c \cot \emptyset_{p}\right)
$$

Where $q$ is the deviatoric stress and $\psi_{m o b}$ is the mobilized dilation angle. The mobilized dilation angle is computed from mobilized friction angle $\emptyset_{m o b}$ and the constant volume friction angle, $\emptyset_{c v}$ in the following manner:

The hardening rule is:

$$
\sin \psi_{m o b}=\sin \emptyset_{m o b}-\sin \emptyset_{c v}
$$

$$
d \sin \emptyset_{m o b}=3 K_{G}^{p}\left(\frac{p^{\prime}}{p_{A}}\right)^{n p} \frac{p_{A}}{\sigma_{\text {max }}^{\prime}+\sigma_{\text {min }}^{\prime}}\left(1-\frac{\sin \emptyset_{m o b}}{\sin \emptyset_{p}} R_{f}\right)^{2} d \lambda
$$

Where $K_{G}^{p}$ is the shear modulus, $n p$ is the plastic shear modulus exponent, $R_{f}$ is the failure ratio and $d \lambda$ is the plastic shear increment.

During primary loading $K_{G}^{p}$ is equal to $K_{G_{0}}^{p}$, which is an input parameter. However, upon secondary loading it is replaced by the updated plastic shear modulus:

$$
K_{G_{i}}^{p}=K_{G_{0}}^{p}\left(4+\frac{n_{\text {rev }}}{2}\right) k_{\text {dens }} f_{a c_{\text {dens }}}
$$

Where $n_{r e v}$ is the number of shear stress reversals from loading to unloading and vice versa, $k_{\text {dens }}$ is a factor between 0.5 and 1.0 required to correct the densification rule and $f_{a c_{\text {dens }}}$ is the densification factor extracted after curve fit.

Usually, when designing in earthquake-prone areas, where determining the liquefaction potential is the goal of calculation, the methods to determine the parameters of the UBC3DPLM model are laboratory tests on a dynamic triaxial device or a dynamic simple shear device. However, in many cases, only data from static triaxial (CD TxC) or field tests (SPT) are available. For this reason the UBC3D-PLM model implements a specific formulation with input parameters based on this tests.

\section{Simulation of seismic effects}

As part of this study, a model of a multi-story residential building (3-9-15 floors) was modeled in the PLAXIS software package. Floor height - 3m. Groundwater level is at ground level (Fig. 1). The parameters of the base soil which used for UBC3D-PLM model and for Linear Elastic model are given in the table:

Table1. Input parameters for the calculation.

\begin{tabular}{|c|c|c|c|}
\hline & Parameter & UBC3D-PLM & Linear Elastic \\
\hline \multirow{2}{*}{\begin{tabular}{c}
. \\
\cline { 2 - 4 }
\end{tabular}} & $\gamma_{u n s a t}\left[\mathrm{KN} / \mathrm{m}^{3}\right]$ & 19.7 & 19.7 \\
\cline { 2 - 4 } & $\gamma_{\text {sat }}\left[\mathrm{KN} / \mathrm{m}^{3}\right]$ & 21.80 & 21.8 \\
\hline
\end{tabular}




\begin{tabular}{|c|c|c|c|}
\hline & $e_{\text {init }}$ & 0.74 & 0.74 \\
\hline & $\overline{\mathrm{E}[k P a]}$ & 98000 & 98000 \\
\hline & $v$ & $\mathrm{n} / \mathrm{a}$ & 0.3 \\
\hline & $\mathrm{G}[k P a]$ & $\mathrm{n} / \mathrm{a}$ & 28000 \\
\hline & $C_{r e f}[k P a]$ & 0.0 & 0.0 \\
\hline & $\varphi\left[^{\circ}\right]$ & 22 & 22 \\
\hline & $\psi\left[^{\circ}\right]$ & 19 & 19 \\
\hline & $k_{x}, k_{y}[\mathrm{~m} / \mathrm{s}]$ & $0.5 e-6$ & $0.5 e-6$ \\
\hline \multirow{14}{*}{ 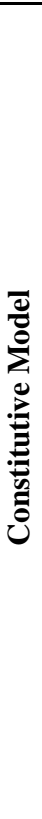 } & $\varphi_{c v}\left[^{\circ}\right]$ & 20 & \multirow{14}{*}{$\mathrm{n} / \mathrm{a}$} \\
\hline & $\varphi_{p}\left[^{\circ}\right]$ & 22 & \\
\hline & $K_{G}^{e}$ & 854.6 & \\
\hline & $K_{G}^{p}$ & 250 & \\
\hline & $K_{B}^{e}$ & 598.2 & \\
\hline & $m e$ & 0.5 & \\
\hline & $n e$ & 0.5 & \\
\hline & $n p$ & 0.5 & \\
\hline & $R_{f}$ & 0.811 & \\
\hline & $P_{A}[k P a]$ & 100 & \\
\hline & $\overline{\sigma_{t}[k P a]}$ & 0.0 & \\
\hline & $f_{\text {ac hard }}$ & 0.20 & \\
\hline & $(N 1)_{60}$ & 7.650 & \\
\hline & $f_{a c_{p o s t}}$ & 0.02 & \\
\hline
\end{tabular}

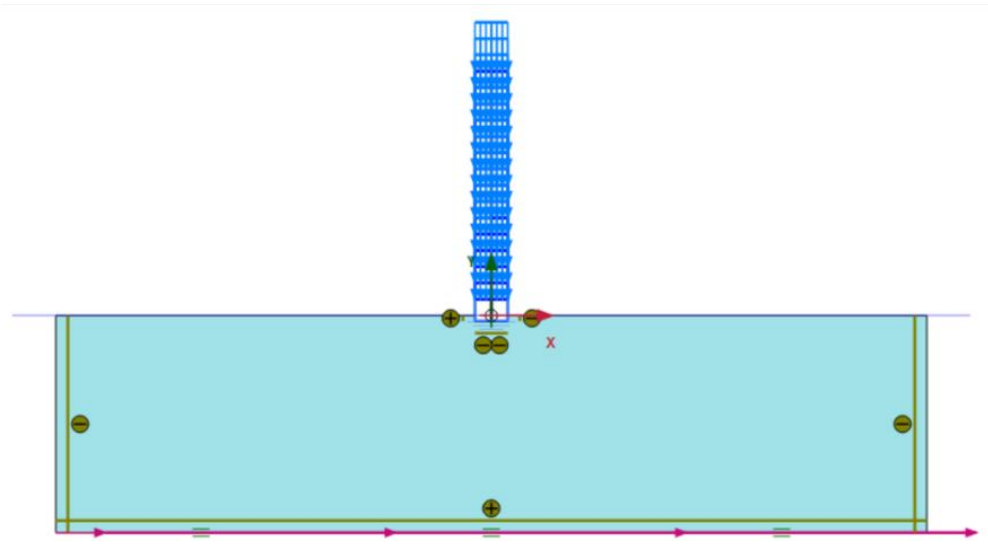

Fig. 1. Design scheme of the model.

Recording of earthquake accelerations with a magnitude 5.40 (in the Richter open scale) and a peak value of $239.87 \mathrm{~cm} / \mathrm{sec}^{2}$ is shown in Fig. 2 


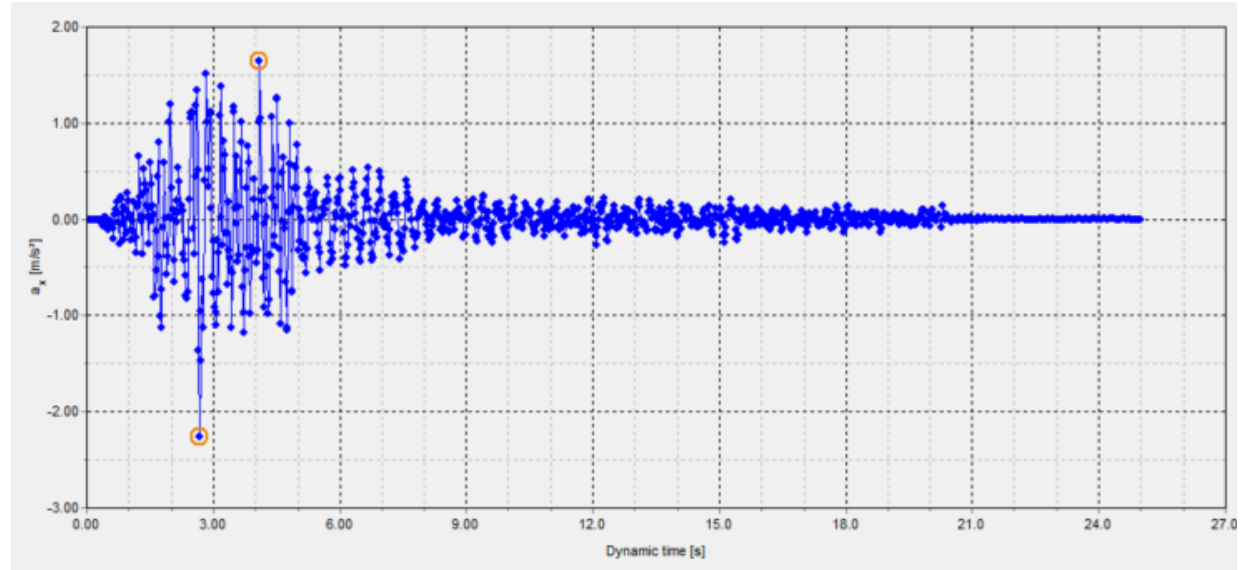

Fig. 2. Dynamic load: recording earthquake accelerations.

\section{Results}

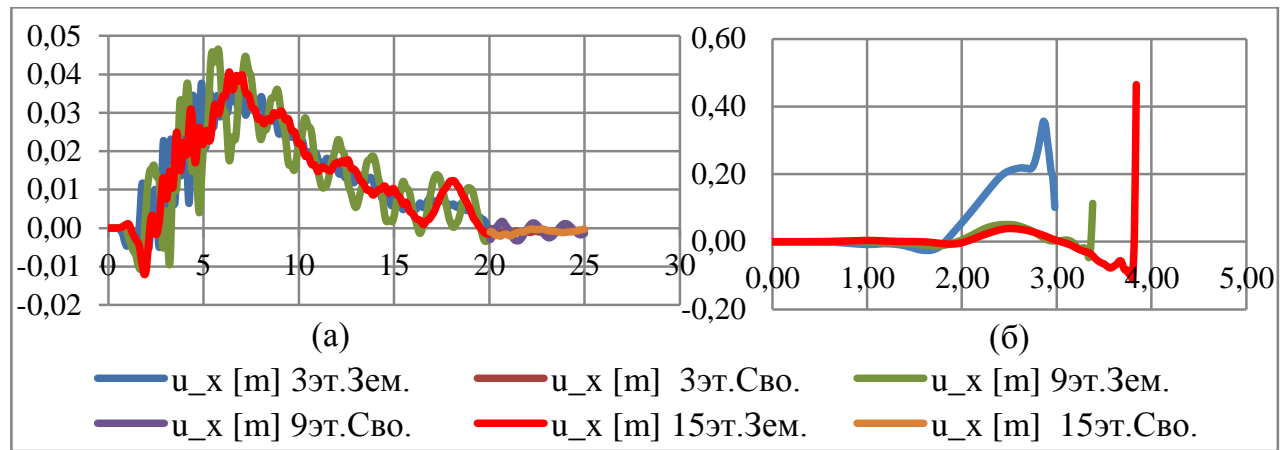

Fig. 3. Dependence the horizontal movement at the top of the building with the dynamic time of seismic impact. a. Linear Elastic model, 6. UBC3D- PLM model.

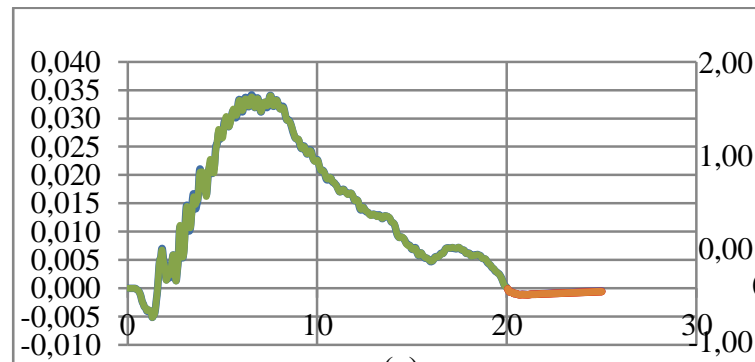

(a)

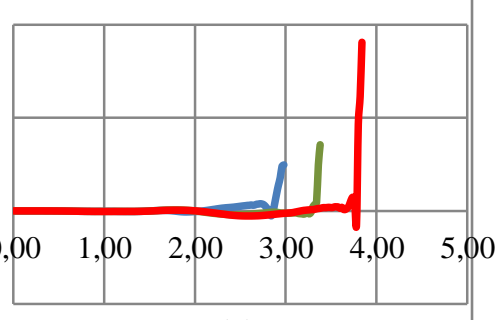

(б)

$$
\begin{array}{ccc}
\mathrm{u} \_x_{\mathrm{m}} \text { 3эт.Зем. } & \mathrm{u} \_\mathrm{x}[\mathrm{m}] \text { 3эт.Сво. } & \mathrm{u} \_\mathrm{x}[\mathrm{m}] \text { 9эт.Зем. } \\
\mathrm{u} \_\mathrm{x}[\mathrm{m}] \text { 9эт.Сво. } & \mathrm{u} \_\mathrm{x}[\mathrm{m}] \text { 15эт.Зем. } & \mathrm{u} \_\mathrm{x}[\mathrm{m}] \text { 15эт.Сво. }
\end{array}
$$

Fig. 4. Dependence the horizontal movement at the bottom of the building with the dynamic time of seismic impact. a. Linear Elastic model, 6. UBC3D- PLM model. 


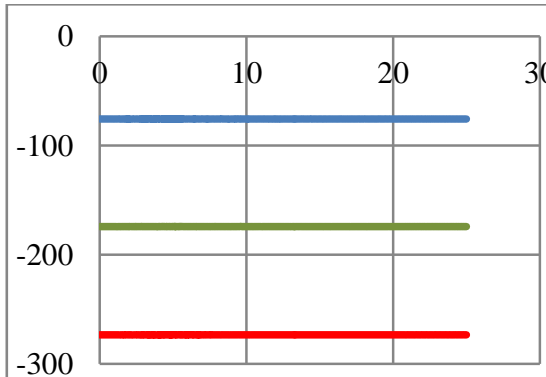

(a)

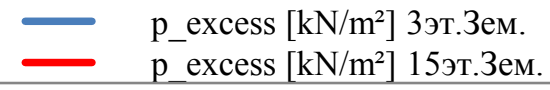

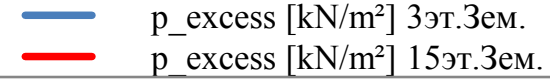

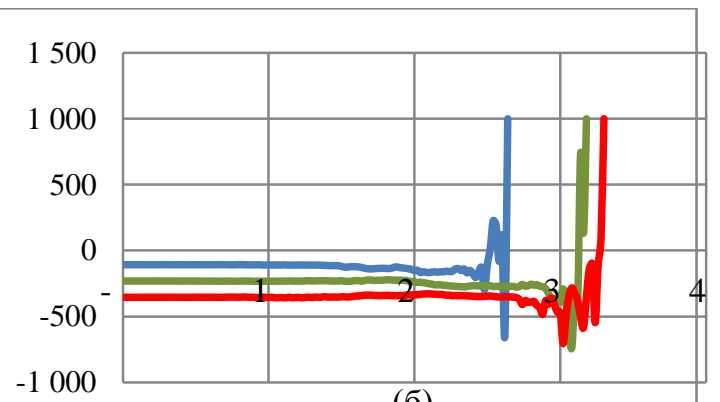

(б)

Fig. 5. Dependence the excess pore pressure at the bottom of the building with the dynamic time of seismic impact. a. Linear Elastic model, б. UBC3D- PLM model

In this obtained results, it is shown that the horizontal displacements at the top of the building do not exceed $5 \mathrm{~cm}$ (Fig. 3a), and at the bottom do not exceed $3.5 \mathrm{~cm}$ (Fig. 4a) in Linear-elastic model. At the same time, results of the calculations based on UBC3D-PLM model showed that the building collapses (Fig. 3b, 4b).

Results of the calculations using UBC3D-PLM model showed (Fig. 5b) that the soil completely loses its bearing capacity as a result of high pore pressure, as a results of occurring liquefaction caused by a seismic load in a few seconds after its start, which in turn leads to collapse of the building, which wasn't recorded in the calculations using Elastic linear model (Fig. 5a).

\section{Conclusions}

Based on the analytical results the following conclusions can be obtained:

- When subjected to dynamic or cyclic loading, the UBC3D-PLM model generates plastic strains when mobilising the soil's material strength (shear hardening). A Rayleigh damping can be taken into account to simulate soil's damping characteristics.

- The UBC3D-PLM model has been developed to predict the dynamic behavior of noncohesive soils, in particular for modeling the excessive pore pressure with undrained behavior and liquefaction.

- UBC3D-PLM model is a fairly easy-to-use, since most of the soil parameters can be obtained from the field test (SPT).

- Results of the simulation showed the difference in the behavior under the impact of an earthquake in UBC3D-PLM model compared with the elastic behavior in the Linear Elastic model. In addition, results of calculations of excess pore pressure using Linear Elastic model in the case of fully water-saturated soils are not correct, therefore, it is recommended to use the UBC3D-PLM model to assessment the seismic impact.

This study was carried out as a part of preparing the $\mathrm{PhD}$ dissertation "The interaction of the foundations with the base soil under seismic loads, taking into account the rheological properties of soils" in Moscow state university of civil engineering. The authors are grateful to Plaxis for providing access to the UBC3D-PLM digital library, and Zaven G. Ter-Martirosyan for his suggestions, criticism and encouragement. 


\section{References}

1. GOST R56353, Soils. Laboratory methods for determination of soil dynamic properties, 40, (2015)

2. ASTM D47667-04, Standard Test Method for Consolidated Undrained Triaxial Compression Test for Cohesive Soils, 13, (2004)

3. A. Petalas, V. Galavi, PLAXIS Liquefaction Model UBC3D-PLM, 45, (2012)

4. A. B. Tsegaye, Plaxis liquefaction model,45, (2010)

5. A. Leara, R.B.J. Brinkgreve, Site response analyses and liquefaction evaluation, 42, (2015)

6. Eurocode 8, Design of structures for earthquake resistance, Part 1: General rules, seismic actions and rules for buildings, (2004)

7. A. Z. Ter-Martirosyan, Interaction of the foundations with the base soil under cyclic and vibration impacts, taking into account the rheological properties of soils, 190, (2010)

8. N. D. Krasiniov, Dynamic properties of soils and their determination methods, 242, (1970)

9. P. L. Ivanov, Liquefaction of sandy soils, 260, (1962)

10. S. B. Ukhov, V. V. Seminov, V. V. Znamenski, Z. G. Ter-Martirosyan, S. N. Chernychev, Soil mechanics-Bases and foundations, 566, (2002)

11. N. A. Tsytovich, Soil mechanics, 272, (2009)

12.Z. G. Ter-Marttirosyan, A. Z. Ter-Martirosian, I. S. Sobolov, Experimental and theoretical basis for determining the mechanical properties of sandy soils under dynamic effects, 48, (2015)

13. M. Jaro, Interaction of two-layer base with foundations under static and dynamic loads, $176,(2013)$

14. S. I. Stanislavovich, Creep and vibro-creep of sandy soils of foundations of buildings and structures, 150, (2014) 